International Journal of Physical Modelling in Geotechnics Volume 18 Issue 2

Large-scale physical modelling of soil-filled masonry arch bridges Augusthus-Nelson, Swift, Melbourne, Smith and Gilbert
International Journal of Physical Modelling in Geotechnics,

2018, 18(2), 81-94

https://doi.org/10.1680/jphmg.16.00037

Paper 1600037

Received 20/06/2016

Published online 08/02/2017

Accepted 07/01/2017

Keywords: brickwork \& masonry/bridges/models (physical)

Published with permission by the ICE under the CC-BY licence

http://creativecommons.org/licenses/by/4.0/

\title{
Large-scale physical modelling of soil-filled masonry arch bridges
}

Levingshan Augusthus-Nelson BEng, PhD

Lecturer, School of Computing, Science \& Engineering, University of Salford, Salford, UK

Gareth Swift PhD, CEng, MIMMM

Senior Lecturer, School of Earth \& Environmental Science,

University of Portsmouth, Portsmouth, UK (corresponding author: gareth.swift@port.ac.uk)

Clive Melbourne PhD, CEng, MICE

Formerly of School of Computing, Science \& Engineering, University of Salford, Salford, UK

\author{
Colin Smith MA, PhD \\ Senior Lecturer, Department of Civil and Structural Engineering, University \\ of Sheffield, Sheffield, UK
}

Matthew Gilbert PhD, CEng, MICE

Professor, Department of Civil and Structural Engineering, University of Sheffield, Sheffield, UK

The presence of soil backfill has been shown to have a significant influence on the load-carrying capacity of masonry arch bridges, with the soil fill providing a number of important functions, including inter alia, the distribution of surface loads and passive resistance to arch deformation during loading. Large-scale physical modelling allows highquality data to be collected under controlled conditions, while enabling essential aspects of the interaction between the soil fill, the masonry arch and the abutments to be observed. This paper considers the design and construction of a unique test facility that allows large-scale soil-filled masonry arch structures to be studied under both quasi-static and cycling loading regimes. The key challenges that were needed to be overcome to develop this facility are presented and discussed.

\section{Introduction}

The masonry arch bridge can be considered as a highly effective soil-masonry composite form, the behaviour of which has in the last 25 years become the subject of in-depth research. At the University of Salford, research has focused primarily on the development of a large-scale experimental facility, driven by the desire to gain a better understanding of the physical behaviour of masonry arch bridge structures in order to facilitate the development and validation of numerical analysis models. Initially, this research focused on the behaviour of arch barrels, subjected to quasi-static and then cyclic loading regimes. More recently, investigations have turned to assessing the influence of soil backfill on bridge behaviour. As an integral part of this continuing programme of research, a major experimental facility has been developed to allow the construction and testing to failure of full-scale, soil-filled, masonry arch bridges. The development and subsequent significant modification to this facility is the main focus of this paper.

\section{Background}

Laboratory model bridges enable detailed measurements to be taken but do not necessarily adequately represent the complexity of real bridges. Although load tests on bridges in the field can provide important information about real response, often very little useful information is made available apart from the geometry and load against deflection response (e.g. as in the case of the tests carried out by the UK Transport Research Laboratory in the 1980s and 1990s (Page, 1993)). Even when more measurements are taken, the complex interactions involved mean that the data collected can be difficult to interpret.

Full-scale physical modelling in the laboratory offers a compromise in that the model test arrangement can be designed to ensure essential aspects of the interaction between the soil fill, the masonry arch barrel and the abutments are properly modelled, and that high-quality data are captured.

Specifically, there has been limited work on investigating the influence of the dynamic effects of working loads on the response of the masonry arch bridge system, and the relationship between loading history and bridge capacity has been little studied in the literature, except in the case of bare arch barrels. A key required feature of this facility is to enable researchers to investigate the permissible limit state, the state beyond which incremental damage occurs, and its relationship with the ultimate limit state (ULS).

\section{General arrangement}

To simplify interpretation, in the laboratory the bridge system can be reduced from a three-dimensional system to a twodimensional system, with a central portion of the bridge (only) modelled under essentially plane strain conditions. This allows the composite behaviour of the masonry arch barrel and the surrounding soil fill to be modelled in the longitudinal plane (i.e. parallel to the arch span). To achieve this, the spandrel walls can be excluded and the masonry arch barrel and soil fill 
International Journal of Physical Modelling in Geotechnics Volume 18 Issue 2
Large-scale physical modelling of soil-filled masonry arch bridges

Augusthus-Nelson, Swift, Melbourne, Smith and Gilbert material were contained within a chamber, with very stiff, low friction side walls (Figure 1).

Details of the test chamber incorporating the aforementioned features, and designed to house soil-filled masonry arch bridges have been described elsewhere (Callaway, 2007, unpublished; Swift et al., 2013); however, the essential elements will also be briefly outlined here. The geometry and dimensions of the test rig are shown in Figure 2.

The test chamber was designed to accommodate a masonry arch with geometries similar to those previously constructed and tested at Bolton University during the 1990s (Melbourne and Gilbert, 1995), to allow results to be directly compared. These tests involved the use of $3 \mathrm{~m}$ span, 4:1 (span:rise), segmental arch barrels.

The test chamber itself was constructed using heavy duty steel I-sections to provide adequate stiffness to enable essentially plane strain conditions to be maintained under load. The total limit of lateral deflection was stipulated to be $<1 \mathrm{~mm}$. It was also considered important that end effects should not influence test results, taking into account the anticipated soil-arch failure mechanisms and potential associated deformations of the soil. However, given the length of the test chamber required to satisfy this condition, it was necessary to include several tie bars across the top and bottom of the steel frame to provide adequate lateral stiffness.

One of the principal design requirements for the test chamber was the ability to monitor soil kinematics during load testing, by capturing digital images. As a consequence, one side-wall of the tank was constructed using $50 \mathrm{~mm}$ thick, clear cast, acrylic sheets (the other side was constructed using $50 \mathrm{~mm}$ thick plywood sheets). The clear acrylic material could be readily drilled and cut on site, while still satisfying the design requirement for transparency. The sheeting thickness of $50 \mathrm{~mm}$ ensured minimal side-wall deflections under loading. Both walls had a further $4 \mathrm{~mm}$ 'sacrificial' layer of acrylic sheet placed on their internal faces in order to protect the thicker acrylic windows, as it was found that in smaller-scale tests compaction of the soil immediately adjacent to the clear acrylic windows could cause surface damage. The sacrificial sheets could be replaced between tests with little cost and effort. In addition to lateral stiffness, the effect of side-wall friction also needed to be considered at the design stage, as shear stresses developed at the boundary (front and rear faces of the test chamber) could significantly influence the stresses within the soil mass contained within the test chamber. A number of options were considered and evaluated using a small-scale test rig, with the use of a thin latex sheet greased with a silicone-based sealant providing the lowest coefficient of friction. As a consequence, the full faces of the $4 \mathrm{~mm}$ Perspex sheets were covered in a layer of silicone grease followed by a $0.33 \mathrm{~mm}$ thick latex sheet. For normal stresses $>10 \mathrm{kPa}$, it has been reported that the application of grease gives interface friction angles of $<2^{\circ}$ (Fang et al., 2004).

The latex was attached using strips of tape at the top of the test chamber, and although some care was required in the placement and compaction of soils within the chamber, minimal damage to the latex was observed during the filling process, indicating that this was a simple yet effective means of placing the latex. The use of latex did however reduce the visibility of

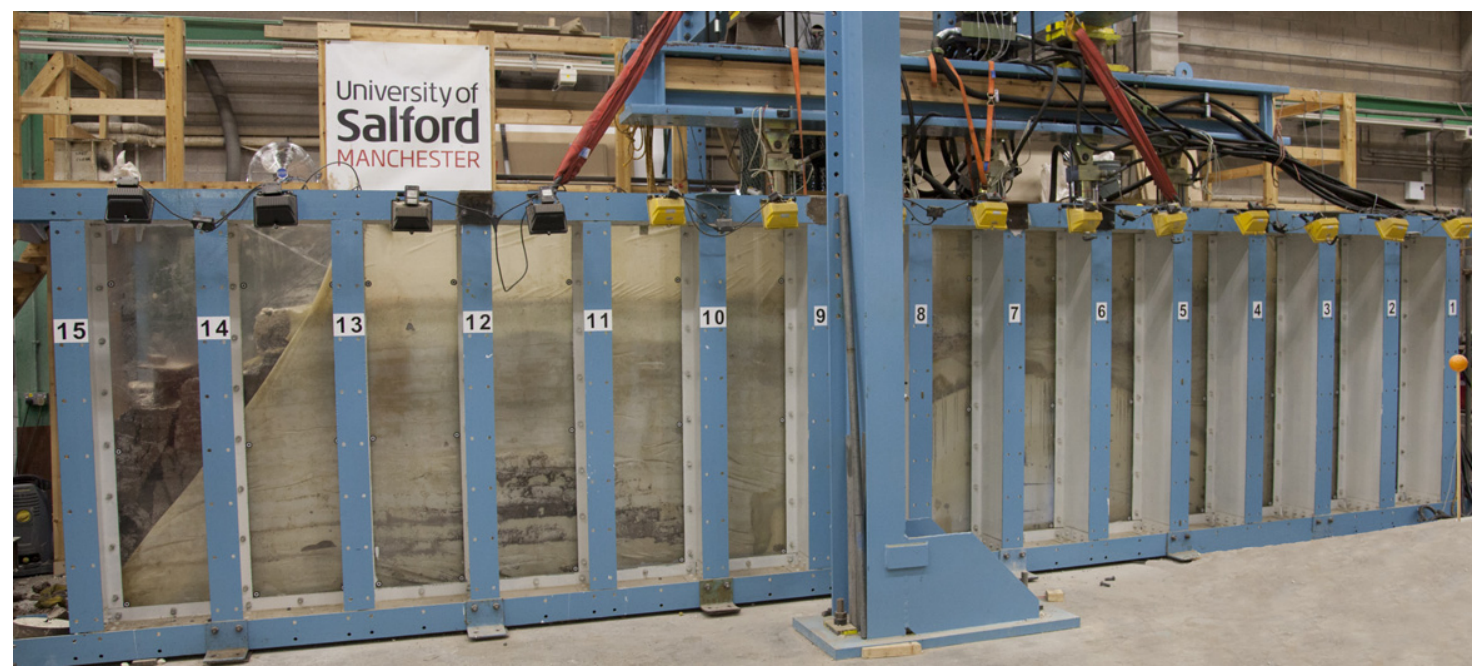

Figure 1. The masonry arch test chamber 

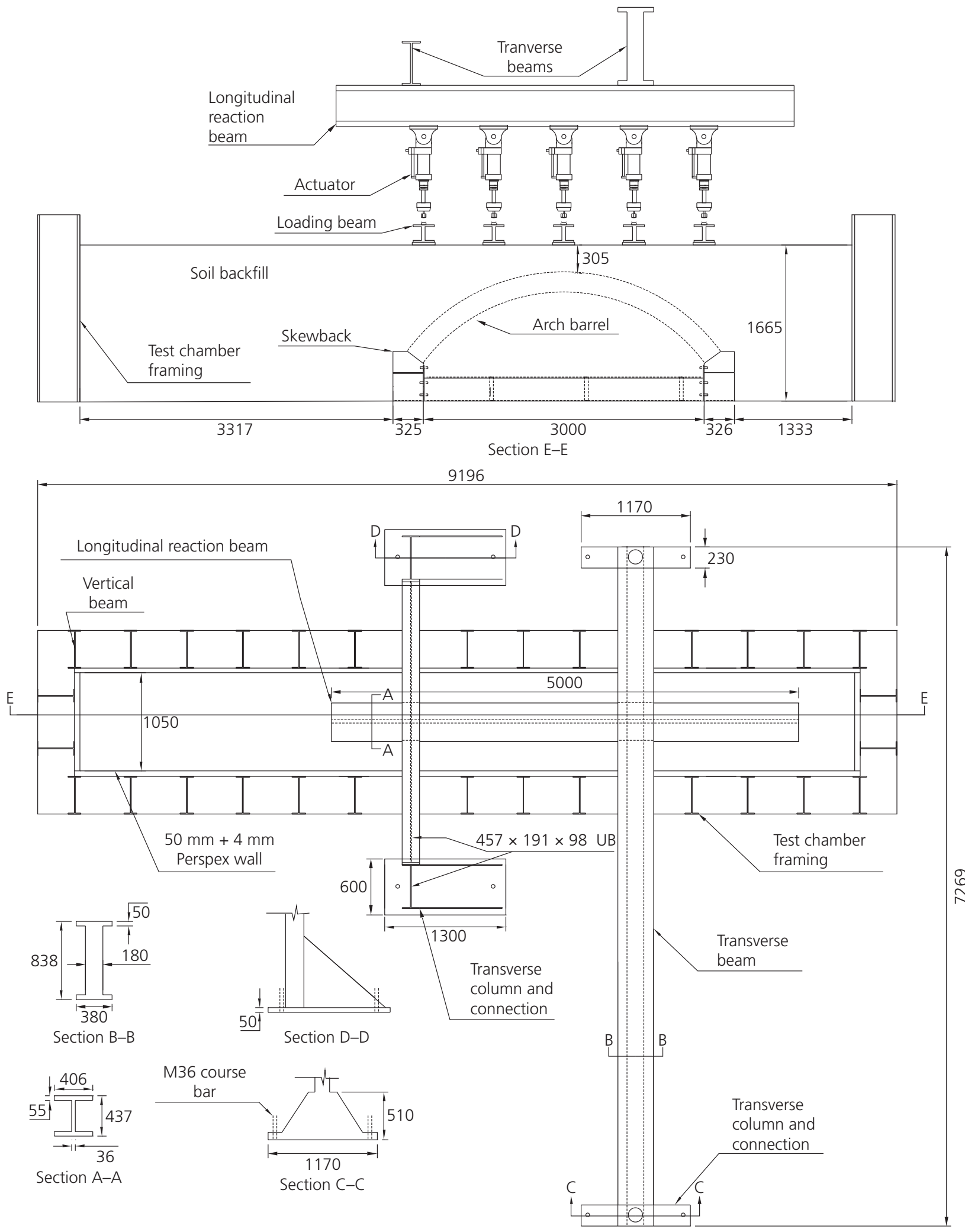

Figure 2. Details of test chamber and reaction frame 
International Journal of Physical Modelling in Geotechnics Volume 18 Issue 2
Large-scale physical modelling of soil-filled masonry arch bridges

Augusthus-Nelson, Swift, Melbourne, Smith and Gilbert the fill material through the acrylic windows. As a consequence, measures had to be taken in order to ensure that the images captured had sufficient detail to allow subsequent analysis and interpretation. The measures adopted depended on the nature of the backfill being used in the tests. Two types of backfill have been used to date: a coarse-grained backfill, comprising graded, crushed limestone and a fine-grained natural clay. In tests using granular backfill, coloured particles were incorporated near the transparent front face of the chamber to provide adequate contrast. In the case of finegrained backfill, texture was provided by incorporating larger, lighter coloured, particles near the transparent front face of the chamber. In addition, powerful floodlights were used to illuminate the transparent windows to reduce any problems with ambient lighting and to reduce reflections.

\section{Reaction frames}

Early tests (Smith et al., 2006) using the test chamber used a simple reaction frame as it was initially anticipated that the chamber would be used primarily for quasi-static load tests to failure. However, with the need to examine the behaviour of masonry arch bridge structures under more complex loading conditions, a more adaptable reaction frame system was subsequently required.

Two parallel portal frames $\sim 2 \mathrm{~m}$ apart and rigidly connected by a cross-beam were each designed to carry a $500 \mathrm{kN}$ reaction load; these are shown in Figure 2. The portal frames connect to a structural strong floor with eight holding down bolts each having a capacity of $250 \mathrm{kN}$. The stiffness of the reaction frame system was designed to be significantly higher than the stiffness of the masonry arch bridge and the surrounding soil material.

A longitudinal beam is attached beneath the portal frames to which the hydraulic actuators and associated manifold are then mounted.

\section{Abutments}

Reinforced concrete abutment blocks supporting the arch barrel which could optionally be anchored (to resist an applied load of $600 \mathrm{kN}$ ) were designed for use in the test chamber. These are indicated in Figure 2, with more details of their structural form in Figure 3. It was considered important to be able to vary the abutment fixity conditions, and, for example, to permit abutment sliding. The abutments were therefore designed and constructed in two parts: a lower section which was bolted directly to the structural strong floor, and a separate upper section, the 'skewback'. During construction a release agent can be applied to the top surface of the lower section prior to the application of a layer of mortar, onto which the upper section is then placed. The upper section is therefore free to slide and/or rotate once the (very limited) initial shear bond and frictional resistance on this interface are overcome. The design allows the bridge to be tested with each of the skewbacks being fixed or free to slide, depending on the test conditions required.

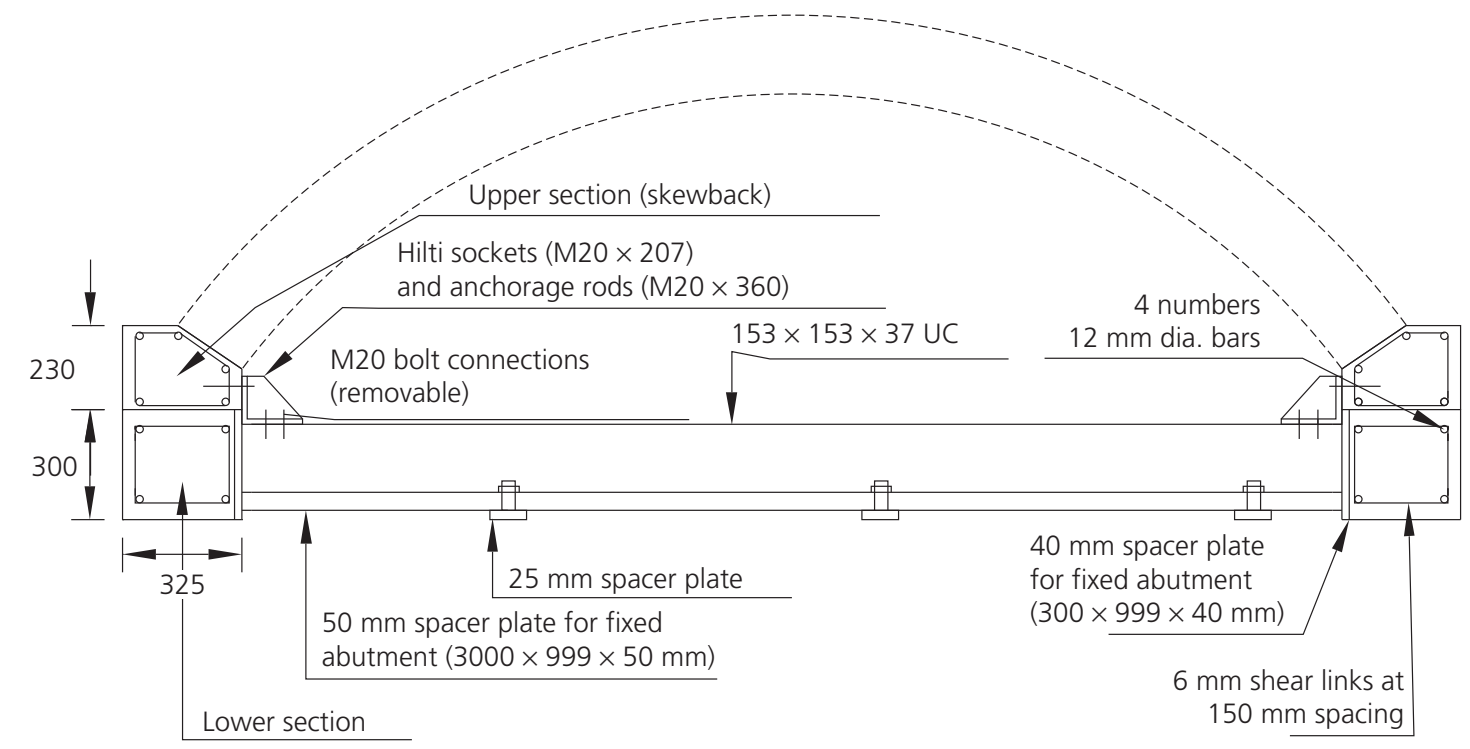

Figure 3. Abutment design details (supporting $3 \mathrm{~m}$ span arch barrels) 
International Journal of Physical Modelling in Geotechnics Volume 18 Issue 2
Large-scale physical modelling of soil-filled masonry arch bridges

Augusthus-Nelson, Swift, Melbourne, Smith and Gilbert

\section{Arch barrel}

The arch barrels of each bridge tested to date were constructed on custom-made curved steel centring (radius $1875 \mathrm{~mm}$ for the default configuration) onto which timber planks can be placed. The planks are then covered with plastic sheeting to prevent adhesion between these and the mortar used to construct the arch barrel, allowing easy removal of the centring at a later stage. Each curved steel beam is supported at either end in such a way as to facilitate readily lowering of the centring. This provides support for the construction of a segmental brickwork arch with an intrados span of $3000 \mathrm{~mm}$ and a rise of $750 \mathrm{~mm}$ for the default configuration. Besides, for the default configuration, Class A Engineering bricks are used with a mortar mix of 1:2:9 - cement:lime:sand by volume, to construct a $215 \mathrm{~mm}$ thick arch barrel with an average width of $1015 \mathrm{~mm}$ (for material properties see Table 1). The default brick and mortar combination was informed by the materials used in earlier bridge tests (Callaway, 2007, unpublished; Melbourne and Gilbert, 1995; Smith et al., 2004) to allow direct comparison of test results.

To carry out material characterisation, appropriate samples are prepared at the time of construction of a test bridge; these include masonry unit prisms to estimate the initial shear strength of mortar joints and compressive strength, and concrete cubes to estimate the compressive strength of mortar.

Table 1. Typical material properties

\begin{tabular}{|c|c|c|}
\hline Properties & Value & Unit \\
\hline \multicolumn{3}{|l|}{ Brick } \\
\hline Mean dimensions & $214 \times 102 \times 65$ & $\mathrm{~mm}$ \\
\hline Density & 2226 & $\mathrm{~kg} / \mathrm{m}^{3}$ \\
\hline Water absorption & 1.90 & $\%$ \\
\hline Initial water absorption & 0.03 & $\mathrm{~kg} /\left(\mathrm{m}^{2} / \mathrm{min}\right)$ \\
\hline Compressive strength & 176 & $\mathrm{~N} / \mathrm{mm}^{2}$ \\
\hline \multicolumn{3}{|l|}{ Mortar } \\
\hline Compressive strength & $1 \cdot 3$ & $\mathrm{~N} / \mathrm{mm}^{2}$ \\
\hline Density & $1470-1570$ & $\mathrm{~kg} / \mathrm{m}^{3}$ \\
\hline \multicolumn{3}{|l|}{ Masonry } \\
\hline Compressive strength & 25 & $\mathrm{~N} / \mathrm{mm}^{2}$ \\
\hline Unit weight & $23 \cdot 7$ & $\mathrm{kN} / \mathrm{m}^{3}$ \\
\hline \multicolumn{3}{|l|}{ Fill (crushed limestone) } \\
\hline Cohesion, $C_{\mathrm{L}}$ & $3 \cdot 3$ & $\mathrm{kN} / \mathrm{m}^{2}$ \\
\hline Internal angle of friction: $\phi_{\mathrm{L}}$ & $54 \cdot 5$ & deg \\
\hline Unit weight & $20 \cdot 0$ & $\mathrm{kN} / \mathrm{m}^{3}$ \\
\hline \multicolumn{3}{|l|}{ Fill (clay) } \\
\hline Natural moisture content & 16 & $\%$ \\
\hline Liquid limit & 37 & $\%$ \\
\hline Plastic limit & 14 & $\%$ \\
\hline Dry density & $1 \cdot 83$ & $\mathrm{Mg} / \mathrm{m}^{3}$ \\
\hline Shear stress at failure & 68 & $\mathrm{kN} / \mathrm{m}^{2}$ \\
\hline Strain at failure & 16 & $\%$ \\
\hline \multicolumn{3}{|l|}{ Fill (ballast) } \\
\hline Unit weight & $16 \cdot 4$ & $\mathrm{kN} / \mathrm{m}^{3}$ \\
\hline
\end{tabular}

One problem affecting brickwork arch bridges is the issue of ring separation, where the arch rings become separated, reducing the ultimate load-carrying capacity (Brencich and Sabia, 2008; Diamanti et al., 2008; Gilbert and Melbourne, 1994). Therefore, in the bridges tested to date, alternate masonry courses comprise 'headers', used to prevent the occurrence of ring separation during testing and to reduce the number of test parameters involved.

To accommodate earth pressure cells (PCs) cavities can be formed in the extrados, along the bridge centre line; 12 such cavities are present in the default configuration.

Following construction of the arch barrel, the walls of the test chamber are placed in position; however, the average width of the test chamber is slightly greater than that of the arch barrel itself. Therefore, in order to prevent fill from subsequently falling through the gap between the arch barrel and the test chamber walls, strips of closed cell foam can be hot glued to the edges of the extrados of the barrel so as to span the gap. The flexible foam accommodates minor lateral arch movements while retaining the fill above, and therefore allows 'free' movement of the arch barrel during load testing.

\section{Arch backfilling}

To date coarse-grained granular backfill (MOT type 1 graded crushed limestone) and a fine-grained soil backfill (clay) have been used. The placement and compaction of these materials at this scale presents some logistical challenges and this section highlights the procedures adopted.

A large hopper suspended from an overhead crane above the test chamber was found to be the most practical way of transferring the soil backfill materials. The intention was to provide a uniform and homogeneous backfill material and therefore careful monitoring of the compaction procedure, using the moisture content and the as-placed density, is essential in order for this to be achieved.

To achieve the maximum density, it was found that compacting the backfill in $120 \mathrm{~mm}$ thick layers was appropriate, starting with an $\sim 105 \mathrm{~mm}$ layer at the bottom and finishing with an $\sim 55 \mathrm{~mm}$ thick layer at the top (somewhat thicker layers were tried initially, but the density achieved was lower). For each layer, the required weight of fill was loaded into the cranemounted hopper for transfer to the rig. The fill can be spread evenly using a shovel to the required thickness, and then compacted to the required specification using a $10.5 \mathrm{kN}(1 \mathrm{t})$ vibrating compaction plate (Amman AVP1040). An average unit density of $2.0 \pm 0.03 \mathrm{Mg} / \mathrm{m}^{3}$ was found to be achievable for the granular backfill placed within the test chamber. For the clay backfill, the same general compaction process can 
International Journal of Physical Modelling in Geotechnics Volume 18 Issue 2
Large-scale physical modelling of soil-filled masonry arch bridges

Augusthus-Nelson, Swift, Melbourne, Smith and Gilbert be used; however, the use of a trench rammer was found to be more effective, particularly given the confined space within the test chamber.

The moisture content is determined by taking samples regularly during placement of the soil (three samples per batch), and in the case of clay backfill, hand-held penetrometer tests can be carried out at regular intervals. Additional steps in the placement of the clay were necessary depending on the moisture content of the 'as-delivered' clay. Where the material was delivered with a moisture content below the optimum, some conditioning of the material was essential to ensure effective compaction. In this case, the material is spread out on the floor of the laboratory and larger clods are broken up to allow moisture conditioning to be carried out effectively. Once the moisture content is adjusted in this way, the clay can be transferred to the hopper and placed and compacted in the manner described previously.

At the end of the filling process, Perth penetrometer tests can also be carried out at discrete locations along the longitudinal centre line of the tank, to aid later strength characterisation.

Sensitive areas adjacent to the walls and the arch barrel itself are compacted with a hand rammer. Each PC within the extrados of the arch barrel is first hand covered by fine sieved limestone ( $\sim 50 \mathrm{~mm}$ depth), and then progressively covered by coarser particles. No compaction is used directly adjacent to or over the cells. However, subsequent layers above the PCs are compacted as previously described. This procedure was used in all tests undertaken to date, irrespective of the backfill used. Clearly, this is a compromise to ensure that PCs are not damaged during the filling process and the PC readings are likely to be influenced by this, making it difficult, for example, to ensure that initial pressure distribution is symmetrical across the arch barrel.

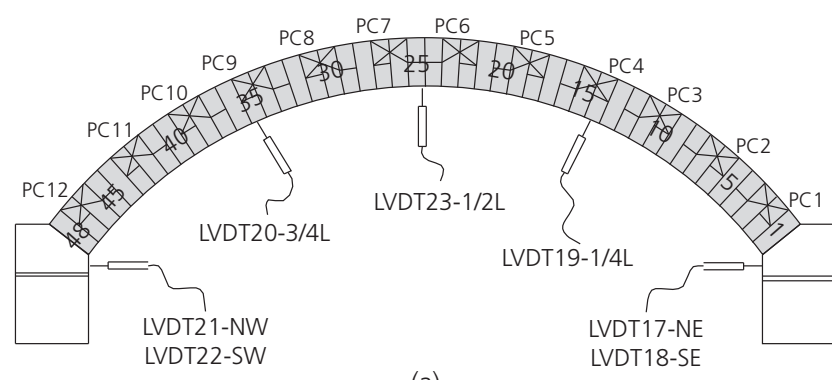

(a)

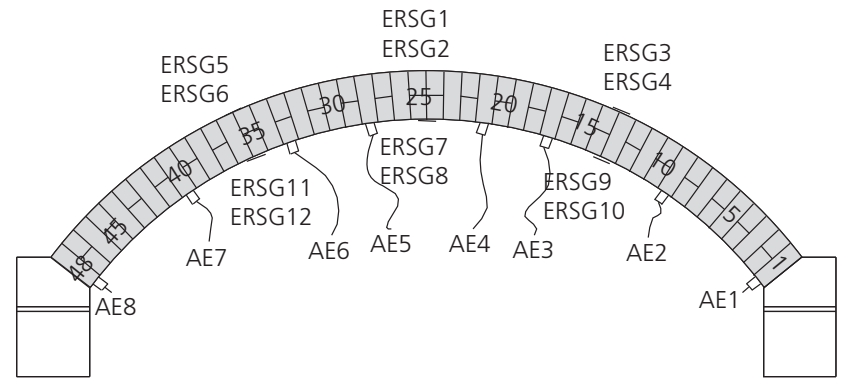

(b)
To ensure adequate contrast for digital imaging, in the limestone tests, from the second fill layer, coloured fill (coal dust) was placed against the windows. This was achieved by placing thin metal plates $50 \mathrm{~mm}$ from the inside face of both sidewalls (front and rear) forming the test chamber. The space between the plates and the chamber side-walls is then filled with coloured fill. After placement of the fill behind the plates, the plates themselves are then removed and the entire layer compacted as described previously. For the clay tests, this procedure was slightly different. The key challenge is to ensure adequate texture and contrast, and so limestone particles are embedded within the clay soil immediately adjacent to the front face of the test chamber.

Before testing, decentring must be carried out by removing the supports underneath the curved steel beams. The centring remains inside the tank, providing independent support for instrumentation while leaving sufficient room to accommodate arch barrel deformation.

\section{Instrumentation}

Displacement transducers, PCs, electronic resistance strain gauges (ERSG) and acoustic sensors can be placed in various positions in order to measure the deformation of the arch barrel and of the test chamber, the soil pressure on the extrados of the arch, strain across mortar joints and change in stiffness due to crack formation. Figure 4 shows the positions of the main arch instrumentation used during tests carried out to date.

\subsection{Deflection}

Seven linear variable differential transformer (LVDT) type displacement transducers positioned perpendicular to the intrados of the arch were used to measure arch barrel deformation during all stages of the tests carried out to date. These gauges

Figure 4. Typical instrumentation on the arch barrel: (a) location of soil PC and linear displacement transducers (LVDT); (b) location of AE sensors and ERSG 
International Journal of Physical Modelling in Geotechnics Volume 18 Issue 2
Large-scale physical modelling of

soil-filled masonry arch bridges

Augusthus-Nelson, Swift, Melbourne, Smith

and Gilbert are capable of resolving displacements down to approximately $\pm 0 \cdot 01 \mathrm{~mm}$.

Moreover, 15 LVDT-type displacement transducers with a range of $50 \mathrm{~mm}$ and accuracy of $0.01 \mathrm{~mm}$ have been used to measure the lateral movement of the test rig itself. These are positioned perpendicular to the vertical faces of the test rig to measure horizontal movements. Monitoring of these during tests carried out to date indicate that relatively insignificant movements $(<1 \mathrm{~mm})$ occur, confirming that the tests are being carried out under largely plane strain conditions.

\subsection{Soil pressures}

A total of 12 wall-surface soil PCs (Kyowa BER-A-500KP12S) were embedded into the extrados of the arch barrels of the majority of the tests undertaken to date to record accurately the pressure exerted on the arch barrel during loading. As described earlier, during construction of the arch barrel, this requires that sockets are created in the extrados of the arch. Once calibrated, PCs are subsequently mortared into these sockets. The PCs have a diameter of $\sim 100 \mathrm{~mm}$ and a rated capacity of $500 \mathrm{kPa}$.

Although the PCs are used to measure the earth pressures acting on the arch barrel at the locations where the cells are installed, it is likely that shear forces may develop due to the interaction between the soil and the arch as it and the surrounding soil deform; this cannot be quantified using the current test set-up. In addition, as the arch deforms, it is possible that arching of the soil may occur, which may make the pressure data difficult to interpret (Ahmad et al., 2015).

\subsection{Acoustic monitoring}

Acoustic emissions (AEs) have been used extensively in structural health monitoring for a number of years and in particular, in relation to masonry arch structures (Carpinteri et al., 2007; Royles, 1991). Detecting crack propagation in the masonry arch barrel is often problematic, however, due to the nature of mortar joints (Carpinteri and Lacidogna, 2007; Invernizzi et al., 2011; Verstrynge et al., 2009). AEs have the ability to detect the real-time fracture activity within the arch barrel over a range of six masonry units (Melbourne and Tomor, 2006). A total of eight acoustic sensors (bandwidth of 20-1000 Hz) were hot glued to the intrados of the arch barrels of a number of test bridges, as shown in Figure 4(b).

\section{$8.4 \quad$ ERSG}

Twelve electronic resistance strain gauges (ERSG) were longitudinally glued to the intrados and the extrados of the arch barrels of a number of test bridges. Two ERSG, one on a masonry unit and one across a mortar joint, were placed at the quarter, mid-span and three-quarter points on the intrados and the extrados. The gauge attached to the masonry unit measures the strain in the unit, which can be used to infer stress. The gauge across the mortar joint measures strain in the mortar joint and the brick. The positions of these gauges are shown in Figure 4(b). Surface strain measurements have been shown to provide useful information regarding the changes in structural behaviour as well as opening of hinges.

\subsection{Data logging}

All data are acquired and logged using a data acquisition system (HBM MGCplus), logging at a rate of $100 \mathrm{~Hz}$.

\subsection{Imaging}

The tank provides 14 bays between the steel vertical members along its side-length. Of these, the middle 12 bays incorporate $50 \mathrm{~mm}$ thick clear cast acrylic windows, as described previously. To capture the soil kinematics by particle image velocimetry (PIV) techniques, a set of seven 21.1 MP, digital single-lens reflex cameras (Canon EOS 5D Mark II) are set up at a distance of $2.4 \mathrm{~m}$ from the windows, such that each camera can image a pair of bays. The cameras are fixed to a steel frame which in turn is fixed to the structural strong floor. This ensures that the camera positions are identical in all tests, and cannot be accidentally altered during a test. In addition, adopting this strategy was found to result in significant time savings associated with camera positioning and set-up. During the tests, the cameras are triggered simultaneously using specialist image capture software (developed by Breeze Systems).

Illumination from above each bay with a halogen lamp has been found to be essential to ensure good image quality and to minimise reflection. Moreover, the internal faces of the I-sections forming the front face of the test chamber were painted white in order to achieve uniform light intensity.

To monitor arch barrel movement, and in particular sliding and/or rotation of the skewbacks, markers are placed on the observable face of these structural elements. Reference markers are also placed on the steel frame of the test chamber and on the acrylic windows at specified discrete locations.

\section{Mechanical and control system design details}

The test programme requires controlled cyclic loading as well as quasi-static loading to simulate working load and load to failure conditions, respectively. A new hydraulic system has therefore been designed to apply these loads to the soil-filled masonry arch structure contained within the test chamber.

Five $200 \mathrm{kN}$ servo-controlled hydraulic actuators (manufactured by Servocon Systems Ltd) were designed for use with the test chamber (Figure 5). Each actuator was fitted with an 


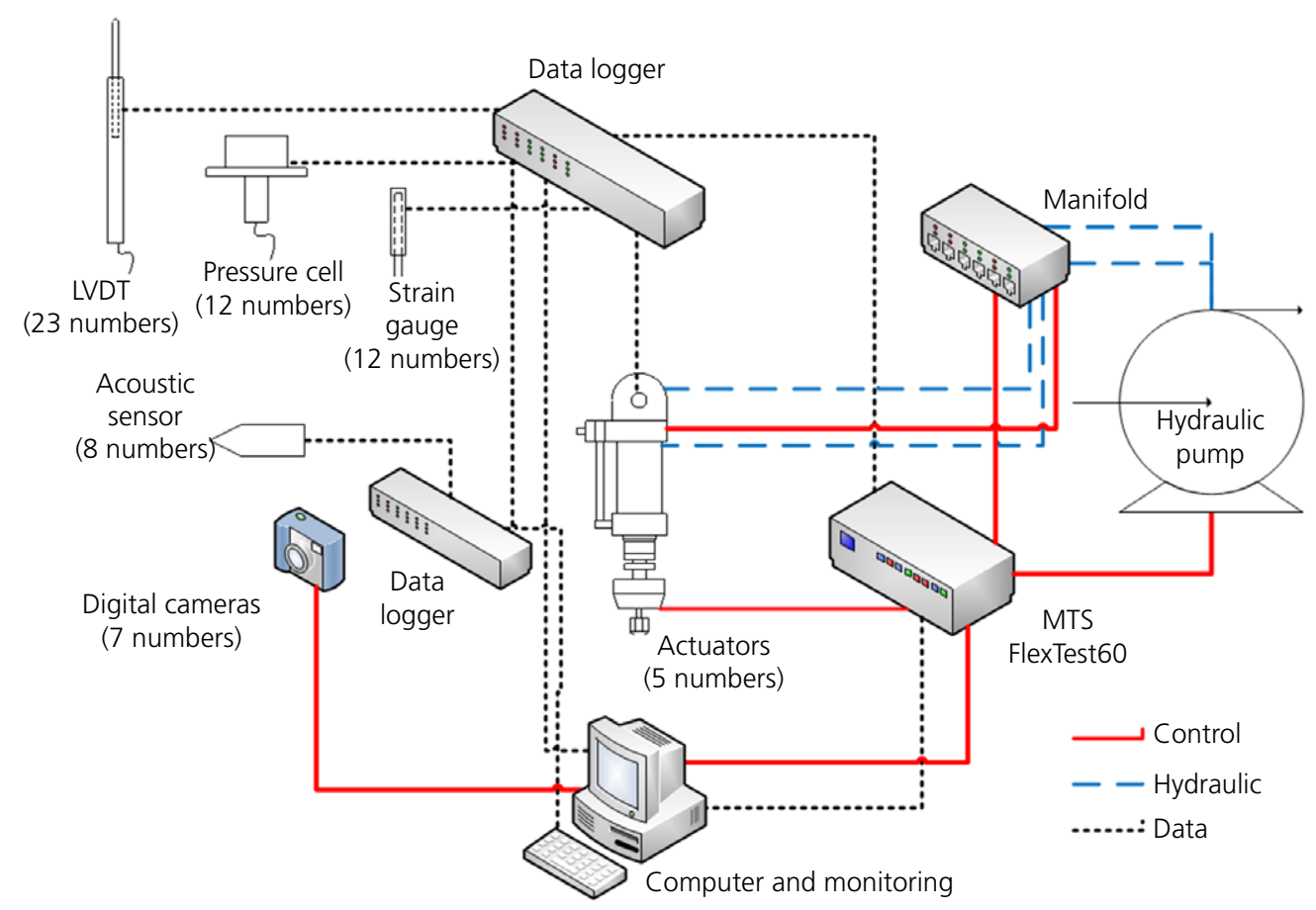

Figure 5. Hydraulic, control system and data connections network diagram

electro-hydraulic servo-valve and a $250 \mathrm{kN}$ capacity load cell The test design requires cyclic loads to be applied independently at five discrete locations at the surface of the soil backfill above the arch barrel: directly above each of the abutments, at the quarter- and three-quarter-span points, and above the crown. An applied peak cyclic load was selected in the range of $40-70 \mathrm{kN}$. This peak load was selected to ensure that the load would remain within the anticipated range of elastic response of the arch and is representative of a typical working axle load.

To determine the capacity of the backfilled arch, a quasi-static load could be applied through any of the five actuators; however, since the assumed worst case loading position is generally considered to be at the quarter-span point, and to remain consistent with previous test programmes, the actuator positioned at the quarter-span point has to date been used to investigate the ultimate load-carrying capacity.

As indicated previously, to simulate a moving load at the surface of the backfill, the phase relationship between adjacent actuators is controlled. The servo-controlled actuators are able to apply preprogrammed, sinusoidal cyclic loads. Each actuator incorporates a load cell with an accuracy of $0.01 \mathrm{kN}$ connected at the bottom of the actuator to measure the applied load. The actuators are directly connected to a longitudinal beam with a single degree of freedom connection and all five hydraulic actuators are connected to a manifold which supplies and controls the hydraulic oil movement between the pump and the actuators. An existing hydraulic pump with an oil flow rate capacity of $90 \mathrm{1} / \mathrm{min}$ and a maximum operating pressure of up to $20 \mathrm{MPa}$ was used.

All the hydraulic components are connected to an eight-channel control system (manufactured by MTS Systems Corporation), with five of these channels being used for the actuators. Each actuator was designed to apply a load in the form of a sine wave moving at a constant velocity across the bridge, with a phase difference of $180^{\circ}$ between adjacent actuators.

\section{Loading arrangements}

The actuators are connected to a longitudinal steel beam supported by two portal frames which allow a 'line' load to be applied to the surface of the backfill directly above the abutments, quarter-point, mid-span and three-quarter point. In each case, the load is applied vertically through a steel loading beam resting on a $25 \mathrm{~mm}$ thick wooden base which is placed on the surface of the backfill, as shown in Figure 6. A single hydraulic jack mounted at the quarter-point nearest the east abutment was used to apply a quasi-static load. The loading arrangement is shown in Figure 6. 


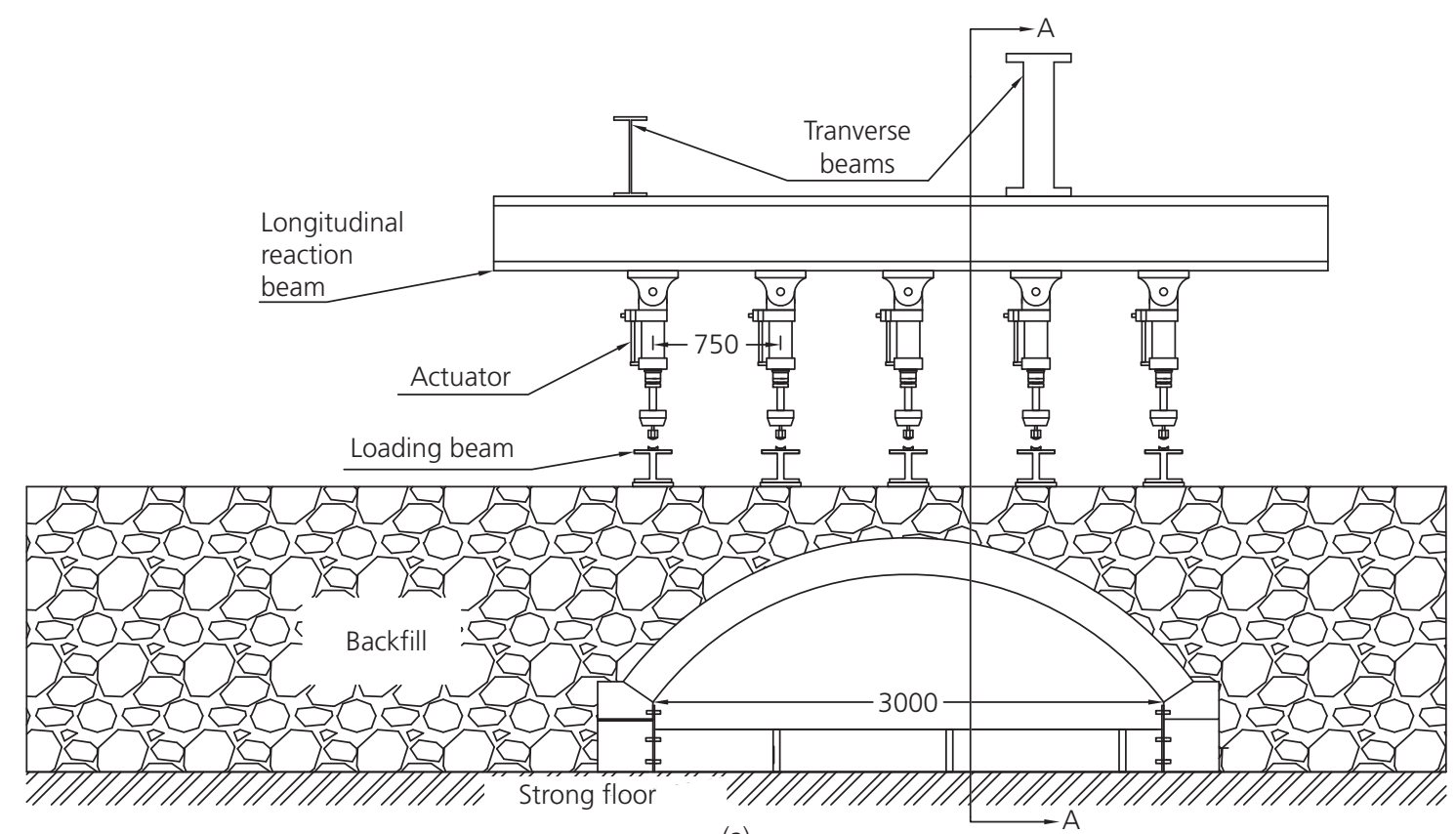

(a)

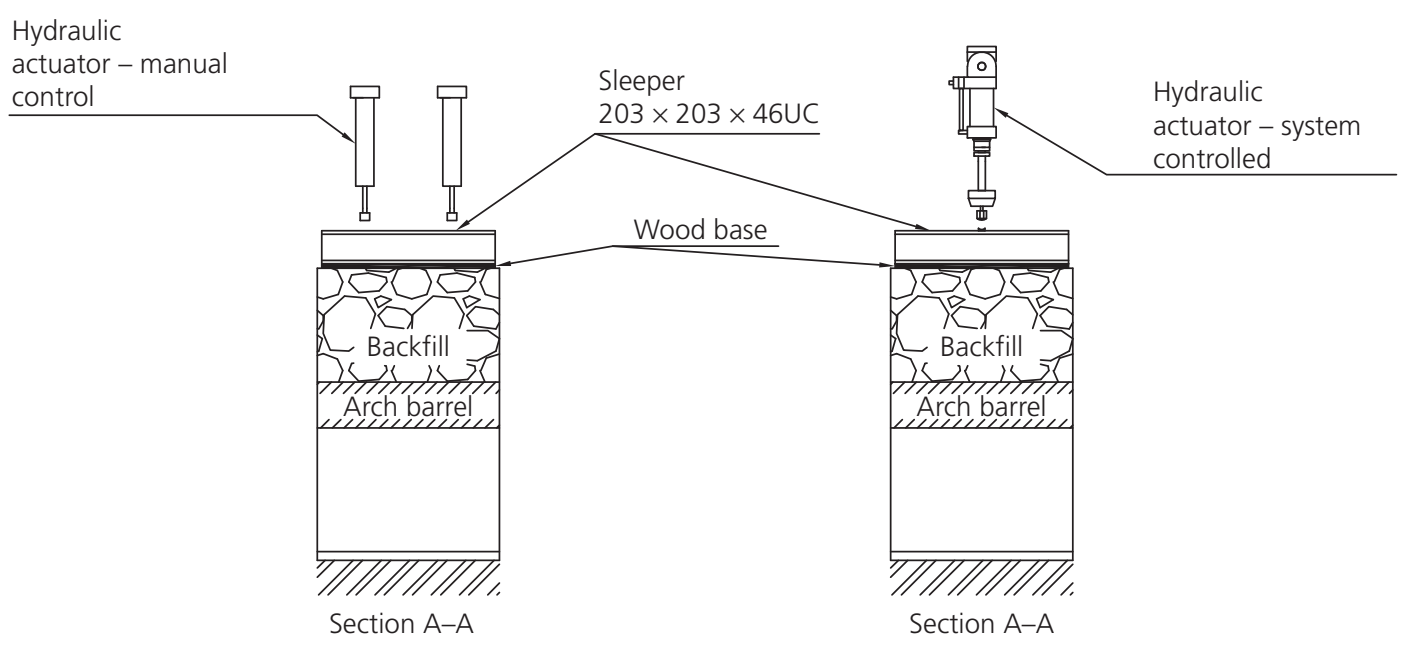

(b)

(c)

Figure 6. Loading arrangements: (a) cyclic loading arrangement, (b) quasi-static loading arrangement, manually controlled (Smith et al., 2006) and (c) quasi-static loading arrangement, system controlled (all the dimensions are in $\mathrm{mm}$ )

\section{Quasi-static loading}

Manual application of loading: In the initial set-up, two hydraulic jacks positioned adjacent to each other, reacting against a steel reaction frame, were used to apply a transverse 'line' load onto the surface of the backfill vertically above the quarter-point of the arch; the load was applied vertically onto the surface of the backfill through a steel loading beam resting on a plywood base which was placed on the surface of the backfill, as shown in Figure 6(b). The load was controlled manually using a hand pump. Following each load increment, a set of images was captured for later analysis and interpretation. This procedure was continued as long as the response of the structure was considered to be broadly linear elastic, based on the load-deflection curve which could be plotted in real time as the test progressed, and where the deflection was measured on the intrados of the arch directly beneath the quarter-point loading position. Beyond this phase displacement control was used, with readings taken once an $\sim 2 \mathrm{~mm}$ increment of displacement had been observed at the quarter-point. 
International Journal of Physical Modelling in Geotechnics Volume 18 Issue 2
Large-scale physical modelling of soil-filled masonry arch bridges Augusthus-Nelson, Swift, Melbourne, Smith and Gilbert
Servo-control application of loading: Following investment in new actuators and a state-of-the-art control system, a single actuator positioned above the quarter-point was used to apply the load, as indicated in Figure 6(c). To observe and quantify possible structural creep behaviour, a new more refined loading procedure was adopted, now using displacement control throughout. In the tests performed to date, the displacement rate was set to $10 \mathrm{~mm} / \mathrm{h}$ up to an initial $5 \mathrm{~mm}$ cumulative displacement and the displacement was then maintained constant for $10 \mathrm{~min}$. This procedure was repeated to $10,15,20,25,30$ and $35 \mathrm{~mm}$ of overall deflection (up to $40 \mathrm{~mm}$ at loading beam level).

\section{Cyclic loading}

The test arrangement allows the relationship between service loading and bridge load-carrying capacity to be explored. In particular, a period of service loading can be represented by the application of cyclic loads to the surface of the soil backfill, while a quasi-static loading regime could be achieved using a single servo-controlled actuator, located above the quarter-span, as previously described.

\subsection{Slow speed cyclic loading}

A slow speed cyclic loading regime was designed to examine the stiffness of the entire structural system (details: $0.01 \mathrm{~Hz}$ with a $50 \mathrm{kN}$ peak load for six cycles, with images captured at $2 \mathrm{~s}$ intervals for a period of $10 \mathrm{~min}$ in the tests performed to date). To avoid the hydraulic actuator load cells losing contact with the loading beam, a minimum valley load was defined $(3 \mathrm{kN})$. This loading regime was repeated after a number of cycles of the normal speed cyclic loading regime $\left(10^{4}, 10^{5}\right.$ and $10^{6}$ cycles).

\subsection{Normal speed cyclic loading}

A normal speed cyclic loading regime was designed to simulate the effects of traffic loading on the bridge (details: $2 \mathrm{~Hz}$ with a peak load of $50 \mathrm{kN}$ and minimum valley load of $3 \mathrm{kN}$ in the tests performed to date). The magnitude, frequency and distribution of loading applied by the five actuators were designed to be broadly representative of traffic moving at $\sim 25-30 \mathrm{mph}$. The arch was subjected to a large number of cycles (e.g. $10^{6}$ ), switching over to the slow speed cyclic loading regime at the stages indicated above. The applied cyclic loading regimes are illustrated in Figures 7(a) and 7(b).

\section{Sample results from pilot tests}

To illustrate the capability of the large-scale testing facility described, tests on three full-scale bridges will be briefly reported. All tests involved nominally identical $3 \mathrm{~m}$ span arch barrels, but each was subjected to different loading regimes.

\subsection{Applied loading regimes}

Bridge EP0 was subjected to quasi-static loading alone, with the test designed primarily to explore the influence of backfill

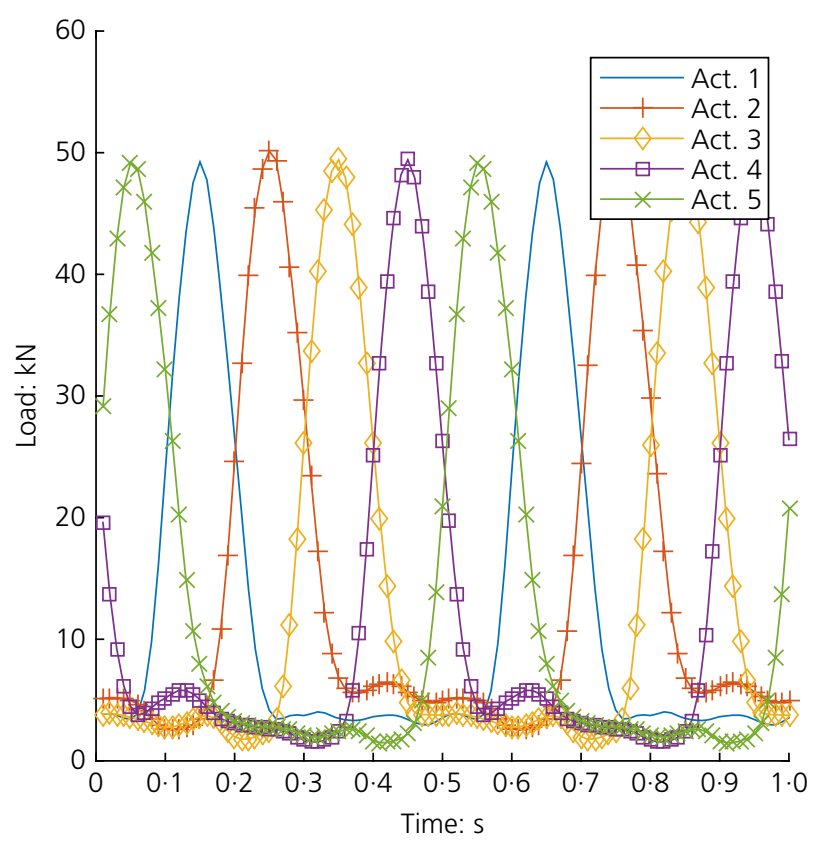

(b)

Figure 7. Sample: (a) slow and (b) normal speed cyclic loading regimes 
International Journal of Physical Modelling in Geotechnics Volume 18 Issue 2
Large-scale physical modelling of soil-filled masonry arch bridges

Augusthus-Nelson, Swift, Melbourne, Smith and Gilbert on ULS load-carrying capacity. A hand pump was used to apply the load.

In contrast, bridge EP1 was subjected to two types of loading, with the test designed to explore the relationship between performance under service loading and ULS load-carrying capacity. Thus, a cyclic load designed to simulate the effects of a prolonged period of service loading on the bridge was applied, and then a quasi-static load was applied at quarterspan to failure, initially using load control and $5 \mathrm{kN}$ load increments, and subsequently using displacement control and $2 \mathrm{~mm}$ displacement increments. The servo-controlled system was used to apply the load, despite using the manual override function.

Bridge EP2 was, like bridge EP0, subjected solely to quasistatic loading. However, to facilitate comparison with the other bridge tests, the loading actuators were in this case controlled entirely by displacements, using the servo-controlled system and measurements from the internal displacement transducer within the actuator. The displacement rate was set to $10 \mathrm{~mm} / \mathrm{h}$.

\subsection{Performance of test bridges}

Applied load against arch radial deflection plots for the three different bridges (EP0, EP1 and EP2) tested are presented in Figure 8. To reduce the 'noise' in the experimental results, a more accurate displacement transducer was externally attached to the actuator and this was used as the control in the test on bridge EP2, in place of the internal displacement transducer which had a significantly lower accuracy and which had been used in the tests on bridge EP1. This contributed to a much smoother load-deflection curve being obtained in the case of the test on bridge EP2 as compared with EP1.

In addition to differences in the loading regimes and systems described, the density of the backfill differed slightly in the three bridges due to the differing ways in which the MOT type 1 graded crushed limestone backfill had been placed. In the case of EP0, the backfill was placed in 11 layers of $150 \mathrm{~mm}$ thickness, achieving an average density of $1.91 \mathrm{Mg} / \mathrm{m}^{3}$, whereas in the case of EP1 and EP2 the backfill was placed in 14 layers of $120 \mathrm{~mm}$ thickness (the first layer is only $105 \mathrm{~mm}$ ), achieving a slightly higher average density of $2 \mathrm{Mg} / \mathrm{m}^{3}$.

Figure 9 shows cumulative soil surface settlement. This also indicates that during the cyclic loading phase the backfill 'bedded down', achieving a more dense state than achieved through compaction alone.

The pressure distributions on the arch barrel at two different stages during EP1 are indicated in Figure 10. This shows the distribution of pressure immediately after backfilling and again

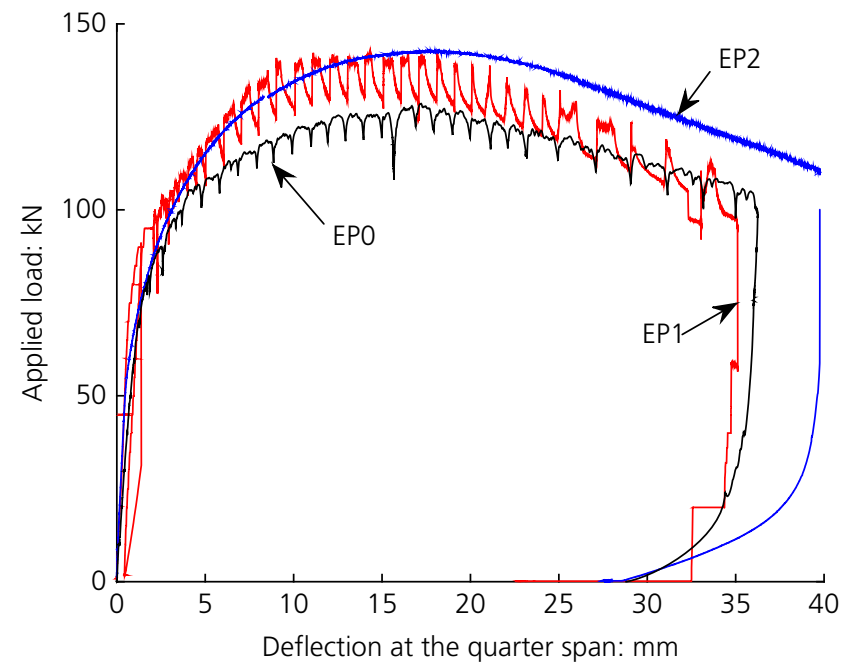

(a)

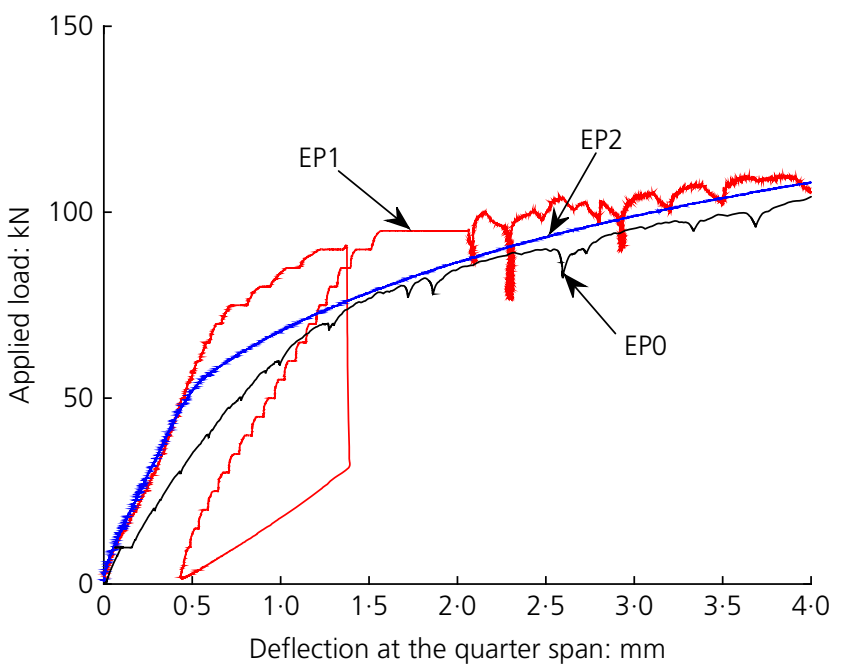

(b)

Figure 8. Load deformation plots for bridges EPO, EP1 and EP2: (a) whole test response, (b) initial response

after completion of the cyclic loading phase. It is evident that the pressure distribution is not symmetrical, which may in part be due to the placement of graded fill material around the individual PCs, as well as due to the confined working conditions within the test chamber itself. The upper curve in Figure 10 illustrates the effects of cyclic loading on the pressure distribution on the arch barrel, showing that the pressures have increased following the cyclic loading phase.

PC readings obtained during the quasi-static loading phase of bridge EP1 are shown in Figure 11. Here the PCs directly below the applied load (e.g. PC number 4) show significant increases in normal pressure, whereas the PCs on the side of 
Large-scale physical modelling of soil-filled masonry arch bridges

Augusthus-Nelson, Swift, Melbourne, Smith and Gilbert

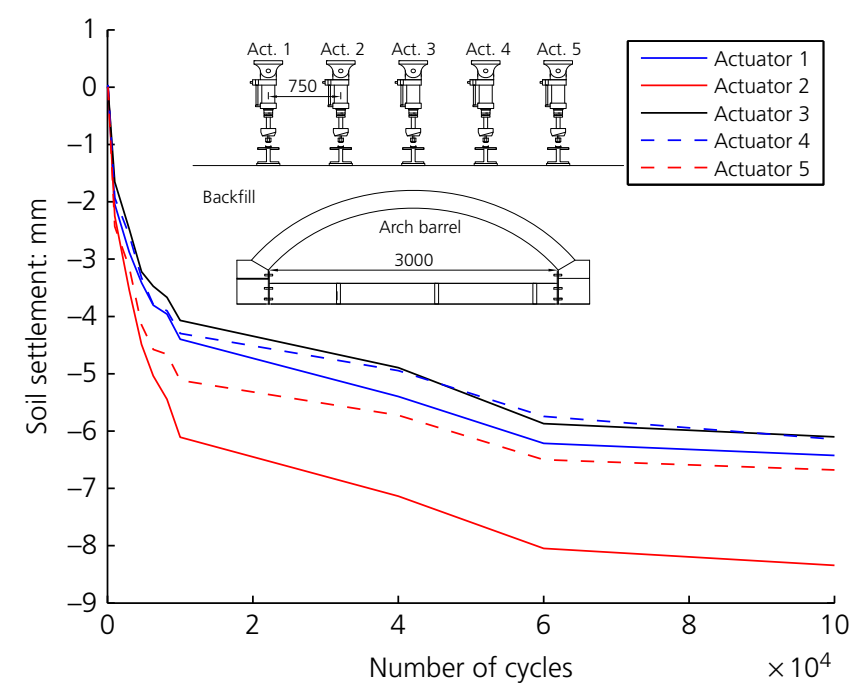

Figure 9. Cumulative soil settlement under each loading beam (EP1 - first $10^{5}$ cycles)

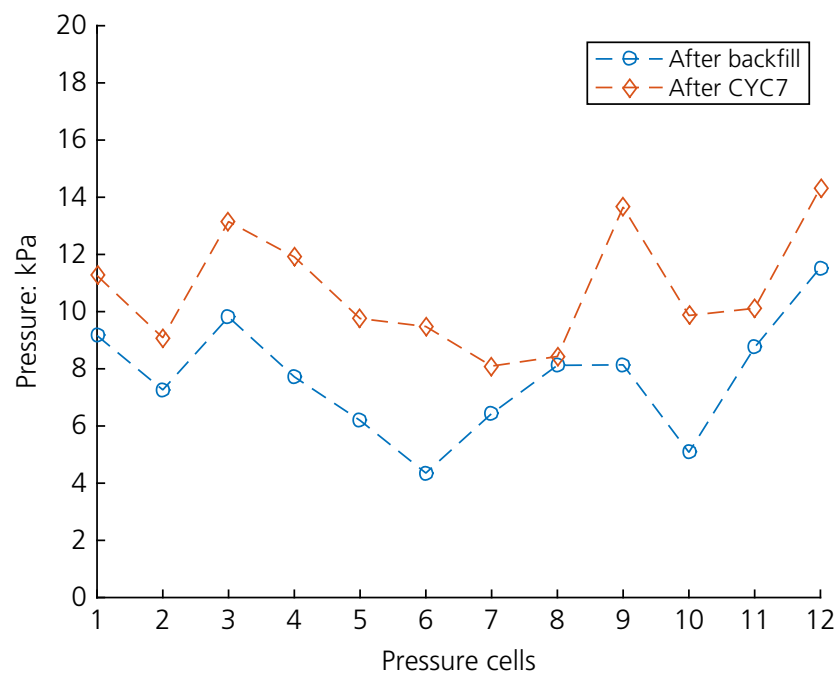

Figure 10. Absolute pressure on the arch barrel after compaction and following cyclic loading (EP1)

the arch remote from the load show much lower increases in normal pressure during the test, as expected.

Figure 12 illustrates the soil displacement at the peak load for EP1. The PIV data are important in confirming interpretation of the PC data. The vectors indicate general movement of soil beneath the loading beam above the quarter-span, but also show clearly the volume of soil involved in resisting the outward deflection of the arch barrel on the passive side of the arch, remote from the load. It is important to note that

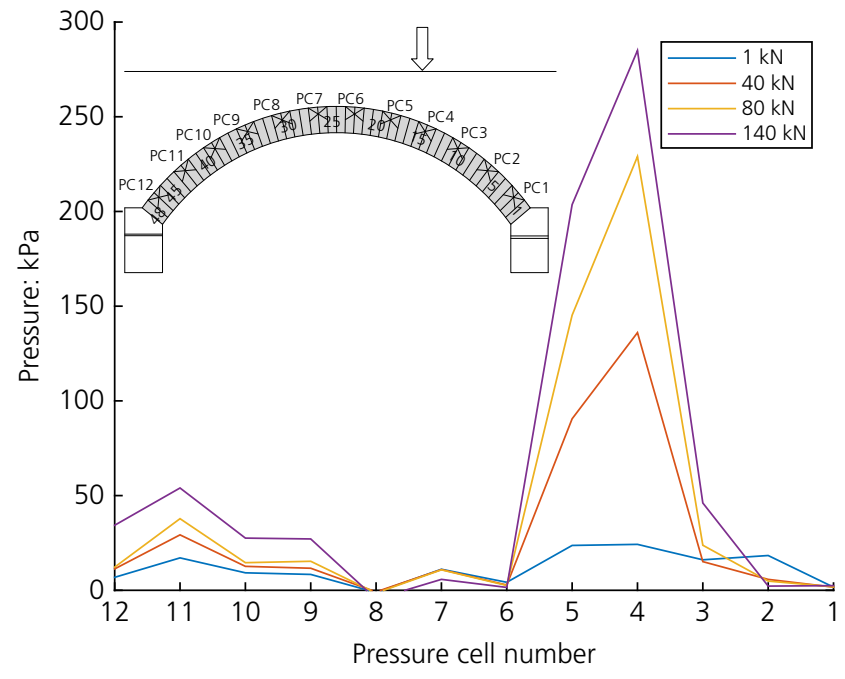

Figure 11. Typical soil pressure profile on arch barrel with increasing quasi-static load at the quarter-span (EP1)

some damage to the latex was observed during the testing caused by soil movements within the chamber, but this did not unduly affect the performance of the image analysis.

The arch barrel was visually inspected prior to the start of every test phase. Prior to the quasi-static load test to collapse on bridge EP1 small $(<1 \mathrm{~mm})$ hairline cracks in the mortar joint between the skewback and the abutment blocks on the west side were observed, although recorded movements of the skewbacks during the cyclic loading phase were small $(<0 \cdot 1 \mathrm{~mm})$.

In the case of all three bridges, during quasi-static load tests cracks were identified adjacent to the east abutment (between brick courses 1 and 2), at the quarter-span (between brick courses 15 and 16) and at the three-quarter-span (between brick courses 28 and 30) (Figure 13, location B and C, respectively). As the applied load increased, the cracks in the arch barrels opened progressively and lateral spreading at the west abutment was observed as sliding occurred along the skewback/abutment interface.

As the applied load was increased further, the sliding at the west skewback/abutment interface ceased and a hinge developed between the west skewback and brick course 48. This behaviour was confirmed using the deformation measurement as shown in Figure 14. The bridge ultimately failed as a four-hinge mechanism, as shown in Figure 13. The physical modelling test programme was conducted so that the critical failure mechanism for a given bridge could be established, and validated using more than one measurement technique. 
International Journal of Physical Modelling in Geotechnics Volume 18 Issue 2
Large-scale physical modelling of soil-filled masonry arch bridges

Augusthus-Nelson, Swift, Melbourne, Smith and Gilbert
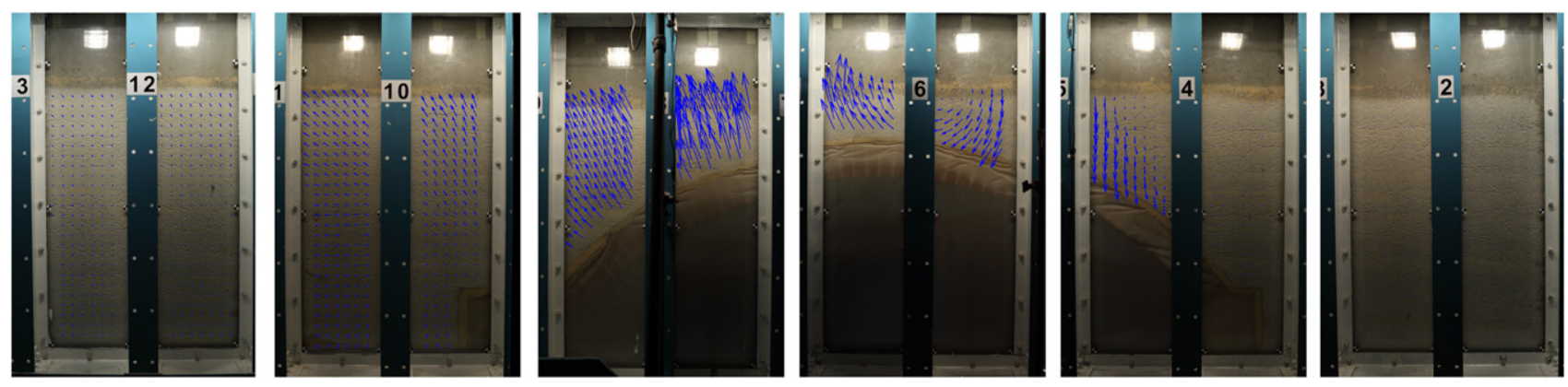

Figure 12. Deformation of soil - four-hinge failure mechanism (EP1)

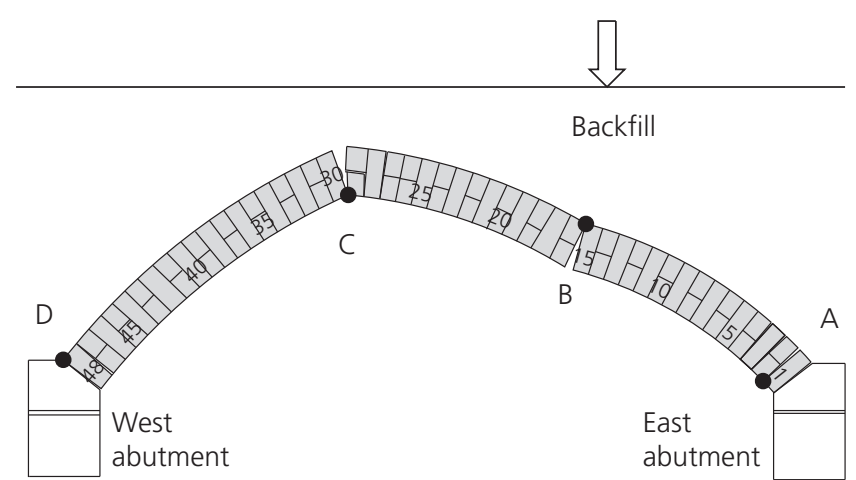

Figure 13. Four-hinge failure mechanisms of arch barrel - EP1

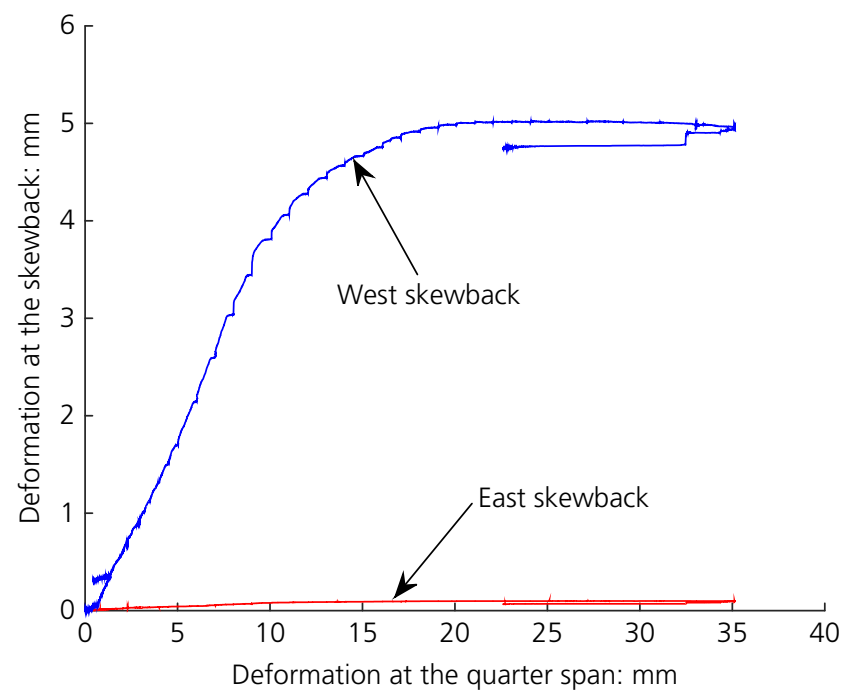

Figure 14. East and west skewback/abutment interface behaviour of EP1

\section{Conclusions}

To investigate the behaviour of soil-filled masonry arch bridges, and to study the interaction between a masonry arch barrel and the surrounding backfill material, a large test chamber and associated hydraulic loading and control system have been commissioned. This allows tests to be carried out on large-scale backfilled masonry arch bridges under quasi-static and cyclic loading regimes.

The hydraulic loading and control systems and the instrumentation generally performed well throughout the tests performed. Cyclic loading effects, of the sort likely to be found in well-trafficked bridges in the field, could be readily discerned (e.g. densification of the soil around the arch barrel, which appears to enhance load-carrying capacity). PIV image analysis data could also be used in conjunction with soil pressure measurements to determine the main features of the soil-structure interaction mechanisms found in masonry arch bridges, both in the region beneath the load and on the passive side of the arch barrel.

\section{Acknowledgements}

The authors acknowledge the support of the UK Engineering and Physical Sciences Research Council (EPSRC), under grant references EP/I014357/1 and EP/I014489/1. They also acknowledge Dr Phillip Callaway for his contribution to the design of the test facility described.

\section{REFERENCES}

Ahmad SHS, Augusthus-Nelson L and Swift GM (2015) Two-dimensional experimental and numerical modelling of a soil-filled masonry arch. Proceedings of XVI European Conference on Soil Mechanics and Geotechnical Engineering, Edinburgh, UK. ICE Publishing, London, UK, pp. 541-546.

Brencich A and Sabia D (2008) Experimental identification of a multi-span masonry bridge: the Tanaro Bridge. Construction and Building Materials 22(10): 2087-2099. 
International Journal of Physical Modelling in Geotechnics Volume 18 Issue 2
Large-scale physical modelling of soil-filled masonry arch bridges

Augusthus-Nelson, Swift, Melbourne, Smith and Gilbert
Carpinteri A and Lacidogna G (2007) Damage monitoring of an historical masonry building by the acoustic emission technique. Materials and Structures 39(2): 161-167.

Carpinteri A, Stefano I and Giuseppe L (2007) Structural assessment of a 17 th-century masonry vault with acoustic emissions and numerical techniques. International Journal of Architectural Heritage 1(2): 214-226.

Diamanti N, Giannopoulos A and Forde MC (2008) Numerical modelling and experimental verification of GPR to investigate ring separation in brick masonry arch bridges. NDT and $E$ International 41(5): 354-363.

Fang Y, Chen T, Holtz R and Lee W (2004) Reduction of boundary friction in model tests. Geotechnical Testing Journal 27(1): 3-12.

Gilbert M and Melbourne C (1994) Rigid-block analysis of masonry structures. Structural Engineer 72(21): 356-361.

Invernizzi S, Lacidogna G, Manuello A and Carpinteri A (2011) AE monitoring and numerical simulation of a two-span model masonry arch bridge subjected to pier scour. Strain $\mathbf{4 7 ( S 2 ) :}$ 158-169.

Melbourne C and Gilbert M (1995) Behaviour of multi-ring brickwork arch bridges. Structural Engineer 73(3): 39-47.

Melbourne C and Tomor AK (2006) Application of acoustic emission for masonry. Strain 42(3): 165-172.
Page J (1993) Masonry Arch Bridges. TRL State of the Art Review. HMSO, London, UK.

Royles R (1991) Acoustic emission monitoring of masonry arch bridges. British Journal of Non-Destructive Testing 33(7): 339-343.

Smith C, Gilbert M and Callaway P (2004) Geotechnical issues in the analysis of masonry arch bridges. Proceedings of the 4th International Conference on Arch Bridges, Barcelona, Spain, pp. 343-352.

Smith CC, Gilbert M, Melbourne C and Wang J (2006)

Development of a test apparatus for full scale modelling of soil-structure interaction in masonry arch bridges. Proceedings of the 6th International Conference on Physical Modelling in Geotechnics. CRC Press, Hong Kong, China, pp. 247-252.

Swift G, Augusthus-Nelson L, Melbourne C and Gilbert M (2013) Physical modelling of masonry arch bridges. Proceedings of 7 th International Conference on Arch Bridges, Trogir-Split, Croatia, pp. 621-628.

Verstrynge E, Schueremans L, Van Gemert D and Wevers M (2009) Monitoring and predicting masonry's creep failure with the acoustic emission technique. NDT and E International 42(6): $518-523$.

\section{How can you contribute?}

To discuss this paper, please email up to 500 words to the editor at journals@ice.org.uk. Your contribution will be forwarded to the author(s) for a reply and, if considered appropriate by the editorial board, it will be published as discussion in a future issue of the journal.

International Journal of Physical Modelling in Geotechnics relies entirely on contributions from the civil engineering profession (and allied disciplines). Information about how to submit your paper online is available at www. icevirtuallibrary.com/page/authors, where you will also find detailed author guidelines. 